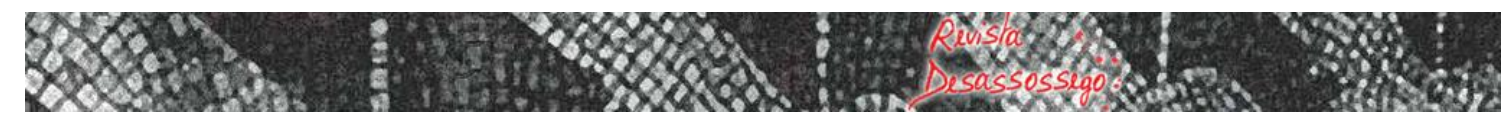

\title{
O DADO INEFÁ VEL: INTUIÇÕES SOBRE O PROCESSO DE CANONIZAÇÃO, À LUZ DE TRAÇOS POÉTICOS PESSOANOS ${ }^{1}$
}

Alessandra Batista ${ }^{2}$

RESUMO: O presente artigo tem por objetivo assinalar e discorrer sobre algumas questões que se erguem e, ao que parece, não se solucionam completamente, ao se pretender definir ou pontuar o motivo pelo qual certas poéticas, e não outras, se tornam canônicas e representativas de uma dada coletividade. Nessa investigação, procurar-se-á problematizar a relação, na modernidade portuguesa, entre a obra de poesia (seus ditos, seus intentos) e o seu suposto alvo de chegada, na medida em que se tornarem claras as dificuldades de acesso e os impasses que aquela viria a impor a este último.

PALAVRAS-CHAVE: Fernando Pessoa; Poéticas; Comparatismo; Canonização.

ABSTRACT: The present article has the intention of emphasizing and discussing about some questions that arise and seemingly cannot be completely solved, in trying to determine why some poetics and not others become canonical and representative of a certain collectivity. In this study, the focus will be on problematizing the relation, in Portuguese modernity, between the poetry work (its statements, its intents) and its presumed target, as the difficulties of access and impasses brought by that first one to this last one become clear.

KEYWORDS: Fernando Pessoa; Poetics; Comparatism; Canonization.

Inicialmente, apresentem-se as duas obras sobre a qual este estudo se debruçará, bem como explicite-se uma primeira motivação dessa escolha. Quanto às obras, trata-se do soneto inglês de número "XXXI", dentre os 35 sonnets de Fernando Pessoa, publicados em 1918; mas possivelmente escritos entre 1901 e 1910; e da ode "Sim", de Ricardo Reis, datada de 8 de julho de 1931. Quanto à seleção, esse primeiro motivador se encontra na questão da distância temporal entre as composições, devido a, com base nela, poder-se propor que o soneto "XXXI", escrito em algum ponto da adolescência do poeta (entre seus 13 e 22 anos), ainda contenha algo de seminal; ou seja, uma espécie de semente que, concomitantemente a manter-se como tal, apontaria já para sua implosão nos diversificados ramos em que, figuradamente, se transformou a sua poesia em língua portuguesa. Ao passo que a ode, tendo sido composta em meados de 1931, se relacionaria aos escritos mais próximos do fim da vida do poeta. Contudo, não sendo o critério temporal algo pelo que se possa definir uma trajetória poética, no que tange aos seus amadurecimentos, mudanças, constâncias etc., outros motivadores, diga-se, mais interessantes, serão encontrados ao longo das análises que se seguirão, à medida que os objetivos específicos desta investigação se tornarem mais evidentes.

Aponte-se que a análise a seguir abordará o soneto de modo a levantar questões e assinalar problemáticas, a partir dele, em vez de pretender solucioná-las. Contudo,

\footnotetext{
${ }^{1}$ Este texto consiste numa adaptação do estudo homônimo produzido para fins de avaliação final da disciplina Formação do Cânone das Poesias Portuguesa e Mexicana Modernas, ministrada pelo Prof. Dr. José Horácio Costa, a quem aqui se registram sinceros agradecimentos.

${ }^{2}$ Mestranda em Literatura Portuguesa pela FFLCH/USP.
} 
buscar-se-á restringir essa esfera de questionamentos àquilo que compete à constituição do sujeito, assumindo que ele esteja se formando ou busque se formar enquanto intérprete de um tipo muito específico de verdade (sobre si mesmo e sobre o mundo).

Primeiramente, invoquem-se alguns dados acerca do contexto de produção do poema, visando sublinhar pontos problemáticos que, já nesse nível da discussão, se ergueriam à compreensão e apreciação da obra, por parte do leitor português.

Após perder o pai em 1893, Fernando Pessoa assiste ao segundo casamento de sua mãe, com o diplomata João Miguel Rosa, que, em razão de sua nomeação como cônsul interino de Durban, leva a família a residir na África do Sul, em 1895. Portanto, é nessa cidade, de grande importância comercial e econômica para o Império Português, porém sob administração política britânica, que o jovem recebe sua instrução primária, ingressando, a 1899, no Liceu de Durban, a Durban High School, e concluindo seus estudos na África, em 1904, com uma boa classificação no "Intermediate Examination in Arts", na Universidade do Cabo, onde já havia sido premiado com o "Queen Victoria Memorial Prize", pelo melhor ensaio de estilo inglês.

Assim, tenha-se em vista que uma parte expressiva de sua formação foi fundamentada e regida por padrões ingleses de educação, nela tendo sido contemplado o mesmo curriculum ministrado e exigido nas melhores escolas do Império Britânico. Portanto, em sua origem, a noção de literatura que se delineia para o jovem Pessoa, está enraizada na literatura inglesa, com a qual estabelece e mantém contato formal, lendo as obras de autores como Shakespeare, John Milton, William Wordsworth, Lord Byron, Alfred Tennyson, Edgar Allan Poe, entre outros.

Partindo-se desta contextualização, parece pertinente supor que suas produções poéticas em inglês tenham assimilado influências desses grandes autores, ainda que não sejam de natureza explícita. Visando corroborar tal pertinência, destaquem-se alguns versos do soneto, e proponha-se uma aproximação entre este e a ode "Intimations of Immortality from Recollections of Early Childhood", de William Wordsworth.

Ao início do soneto "XXXI", vê-se o emprego de maiúsculas nos termos "natureza", "tempo" e "consciência": "I am older than Nature and her Time / By all the timeless age of Consciousness". Como poeta da primeira geração do Romantismo inglês, Wordsworth, a seu tempo, utiliza este recurso, como forma de ampliar a significação do termo visado, transformando-o em símbolo, leia-se, um elemento linguístico que, simultaneamente, serve para representar seu próprio referente e para lhe atribuir um sentido mais abrangedor, muitas vezes, múltiplo ou ambíguo.

A seguinte estrofe de Wordsworth $(1807, \mathrm{~s} / \mathrm{p})$ permitirá verificar a recorrência a esse expediente, bem como certos ecos de sua influência no próprio conteúdo/tema do soneto de Pessoa:

Our birth is but a sleep and a forgetting:

The Soul that rises with us, our life's Star,

Hath had elsewhere its setting,

And cometh from afar:

Not in entire forgetfulness,

And not in utter nakedness, 
But trailing clouds of glory do we come

From God, who is our home:

Heaven lies about us in our infancy!

Shades of the prison-house begin to close

Upon the growing Boy,

But he beholds the light, and whence it flows, $\quad 70$

He sees it in his joy;

The Youth, who daily farther from the east

Must travel, still is Nature's priest,

And by the vision splendid

Is on his way attended;

At length the Man perceives it die away,

And fade into the light of common day.

A leitura integral da ode lançaria ainda outras luzes sobre passagens do poema de Pessoa, bem como permitiria uma extensa e profícua análise interpretativa, sob um viés comparatista. Não obstante, para as linhas deste artigo, sua invocação apresenta outro foco: problematizar a relação entre a obra pessoana em inglês (sendo o soneto um seu representante) e o seu leitor, quando o perfil deste se define como português.

A fim de que se compreenda melhor a lógica dessa problematização e que se estenda a mesma à obra como um todo, fazem-se necessárias algumas ressalvas. Deve estar claro a qualquer discussão que, ao compor em inglês, Pessoa não teria concebido o público português como seu alvo. Na verdade, no caso tão específico e especial desse poeta, não se poderia precisar com muita segurança se ele teria qualquer "público" como destinatário, podendo ser mais acertado pensar nesse destino de sua poesia como sendo ela mesma, ou seja, uma literatura feita para a literatura. No entanto, não se poderá negligenciar, como já se tem feito, o fato de ser precisamente essa poesia, a composta em inglês, aquela com que o jovem Pessoa dialoga para formar suas noções formais acerca dessa arte, bem como para estrear no âmbito literário, enquanto autor.

Aqui começa a se assinalar mais claramente a questão levantada, pois caberá perguntar, portanto, até que ponto o leitor português estará apto a entender com justeza ou a ter um acesso consistente à faceta portuguesa desse seu significativo poeta nacional, se não prestar a devida atenção a esse fato fundamental de sua formação? Sobretudo ao se ter em conta, conforme propõe este estudo, que nas composições condicionadas a essa formação esteja contida uma espécie de gênese do que veio a se tornar a poesia pessoana em língua portuguesa.

Assim, proponha-se que aqui se delineie algo como uma condição a um acesso mais firme e profícuo às chaves de leitura de sua obra como um todo. Sendo esse o caso, tal obra, já tão rica e complexa quando tomada apenas na sua dimensão em língua portuguesa, ganha nova e acentuada complexidade, tornando o processo de sua apropriação pelos âmbitos da cultura e do Estado nacionais uma tarefa ainda mais laboriosa para a coletividade portuguesa - o que, em alguma medida, poderia explicar a menor atenção que se tem dado à produção crítica voltada para esse objeto. Em outros termos, dir-se-ia que, tida como essa condicionante de importância nada marginal, a necessidade de visitar as composições anglófonas de Pessoa se configura como um 
entrave problematizador da relação entre a obra do poeta e seu recipiente sociocultural e político, entrave cuja resolução parece premente, devido a neste recipiente estarem contidos significativos poderes de canonização literária.

Supondo-se a pertinência da visão aqui defendida, a esta altura, pode-se indagar: seria mesmo premente a resolução deste entrave?

Visando a hipóteses de resposta, sem que isso se torne empecilho à sugestão de novas questões, passe-se ao segundo momento da análise, direcionando-se o foco aos elementos internos ao soneto, e, assim, apontem-se os mecanismos de constituição do sujeito e as problemáticas, daí decorrentes, para o tema do estabelecimento do cânone.

Pontuada a questão da formação de Pessoa, e diante da aproximação feita entre este e o poeta romântico Wordsworth, cabe rememorar alguns dos conceitos básicos que nortearam o processo de configuração do sujeito, no Romantismo inglês - em que já se poderá notar rebentos de uma modernidade que se avizinhava. Assim, sublinhe-se o que, nessa configuração, se refere ao ser e estar no mundo, pontuando que essa experiência se deflagra como uma desestabilização e alienação do indivíduo, que não mais se reconhece diante de si e não se delineia de modo seguro e ordenado perante o outro e o mundo que o cerca; o que se dá em decorrência do modo como, gradualmente, vê-se inapto a organizar, acomodar e estratificar a realidade de forma racional e, até certo ponto, aproblemática:

Aspirando à consolidação de suas propostas idealistas ou procurando evadir-se para tempos e espaços longínquos - a Idade Média e o Oriente exótico, principalmente - o artista romântico radicaliza no próprio eu o afastamento de um cenário que o desagrada ou que o frustra. "Os românticos são, antes de tudo, intérpretes do mal-estar que sucedeu ao 'desencantamento do mundo' - à despoetização da vida, gerada pelo refluxo da experiência religiosa, dos ideais heróicos e do espírito de aventura", diz José Guilherme Merquior (1996, 74). Para Vitor Manuel de Aguiar e Silva o mal-do-século, caracterizado pelo pessimismo, pela melancolia, pelo desespero, pela volúpia do sofrimento e pela busca da solidão, exprimiria o "cansaço e a frustração resultantes da impossibilidade de realizar o absoluto" aspirado pelo homem romântico $(1979,481)$. (BARROS, 2010, s/p)

Algo dessa tradição tocante à configuração do eu romântico estaria ecoando no soneto "XXXI"? Tome-se esta nova indagação como uma questão de entrada e de condução para as próximas discussões, nas quais se manterá presente a tese de que as influências da tradição com que o poeta lidou, embora possuindo um relevo que não se deverá desprezar, não se imporiam como decisivas ou cerceadoras do seu fazer poético, pois, conforme podem elucidar as palavras de Carlos Felipe Moisés:

[Fernando Pessoa] É um poeta que não se limita a expressar sentimentos, como é hábito em nossa tradição lírica, mas insiste em se questionar, e à realidade em redor, pondo em xeque, uma a uma, as aparentes verdades e valores em que se apóia a civilização que ainda é, substancialmente, a nossa. (MOISÉS, 2005, s/p)

Ao se reinvocar os versos iniciais do poema (em tradução livre): “Eu sou mais 
velho do que a Natureza e o Tempo dela / Por toda a atemporal era da Consciência afora", proponha-se o questionamento: que notícia o sujeito poderia estar dando de si mesmo, ao se configurar como mais velho, isto é, como anterior à própria Consciência?

A interpretação que aqui se faz desse aparente (ou real) paradoxo, norteia-se pela noção de que o modo de ser e estar no mundo se configuraria, para esse sujeito, como uma dinâmica estática, definida pelo que já se convencionou chamar de ser não sendo (LOURENÇO, 1983, p. 157).

Dessa perspectiva, buscar-se-á apontar, na apreciação dos versos que se seguem, o modo como os conceitos de categoria, identidade e unidade se esfacelariam, à medida que se instauram os movimentos do ser não sendo (PESSOA, 1965, p. 599):

I AM OLDER than Nature and her Time

By all the timeless age of Consciousness,

And my adult oblivion of the clime

Where I was born makes me not countryless ${ }^{3}$.

Ser anterior à consciência e, ainda assim, consciente. Sua constituição caracteriza um excesso de consciência, de lucidez, que o permite estar ciente até mesmo daquilo que lhe foi obliterado. A consciência que esse sujeito supera é a Consciência-símbolo, a abrangente, aquela que pode ser atribuída a toda a humanidade, e na qual se reuniriam dados mais superficiais e imediatos. Todavia, a sua é a não-dita, a não-escrita, nem com maiúscula nem com minúscula: a consciência de se ter consciência, a consciência de sentir, de apreender o mundo com força muito mais brutal em seu interior do que em seu exterior. E esse sentir, por ser consciente, pode se estender até ao sentir daquilo que é olvido e que, no entanto, não se pode olvidar a essa consciência primeva, mais intensa, mais reveladora.

Dessarte, o que é descrito, diga-se, categorizado, como "oblivion" não é "oblivion", e esse não ser torna-se o seu preciso e precioso modo de ser, por estar ligado ou condicionado a um sujeito que também assim se define. Configurada como está, essa obliteração não tem força para amputar do indivíduo a noção de pertença à região olvidada. Obliterada ela está enquanto cor ou forma ("colour or shape"), enquanto terranatal em que se pisa efetivamente: a obliteração se dá como uma inacessibilidade pertinente ao campo físico, material. Porém, o mencionado excesso de consciência do sujeito lhe permite senti-la, possuí-la em seu interior: não há como ser despatriado dessa pátria que se sente e que se sonha em seu íntimo:

Ay, and dim through my daylight thoughts escape

Yearnings for that land where my childhood dreamed,

Which I cannot recall in colour or shape

But haunts my hours like something that hath gleamed

And yet is not as light remembered,

Nor to the left or to the right conceived;

\footnotetext{
${ }^{3}$ A autora desde artigo apresenta, em anexo, uma tradução livre do poema.
} 
Essa terra-natal não é terra, pois se está diante de uma noção de pátria que habita o sujeito, em vez do contrário. E, atravessando o crepúsculo, os seus pensamentos, que são como intuições de um poder iluminador mais intenso que a luz do dia, o advertem quanto à inutilidade de anelar por essa terra enquanto "aquela terra em especial", onde dados fatos(?) possam ter ocorrido. Pois, a todo tempo, tudo o que possa parecer categorizado está em eterna contradição. A terra, da qual ele não pode se lembrar em cor ou forma, se configura como o lugar desejável - um locus amoenus -, por ser onde sua infância teria ocorrido, ao mesmo tempo em que é evocada como a terra a qual sua consciência deve se abster de anelar, e onde sua infância teria apenas sonhado, esquivando-se também ela da obrigatoriedade de cumprimento no tempo e no espaço.

Assim desprovida de sua fisicalidade espacial, essa terra se avulta como assombração: encontra-se munida da idiossincrasia capaz de assombrar o sujeito, tal qual algo que tenha meramente cintilado diante dele, sem ter tido o necessário tempo para se estabelecer de uma vez por todas como luz e, dessa forma, poder lhe indicar alguma direção segura. Trata-se, então, de uma terra-natal, uma pátria que ao invés de se firmar e fornecer um porto-seguro e um distintivo para a constituição do sujeito, para a formação de uma identidade (nacional), se mostra escapadiça, como uma luz que, ao ceder espaço à escuridão, à não-luz, instaura o seu modo de ser: o cintilar (the gleam).

Por conseguinte, na imagem desse cintilar tem-se um vislumbre do mecanismo pelo qual o próprio sujeito se constitui: a dinâmica estática do ser não sendo, a qual se propaga e atinge a constituição de todas as coisas:

And all round me tastes as if life were dead

And the world made but to be disbelieved.

Thus I my hope on unknown truth lay; yet

How but by hope do I the unknown truth get?

Uma vida que se define pela semelhança com a não-vida, leia-se, morte; um mundo que é feito do seu desfazer-se, pois feito apenas para ser desacreditado, tal qual aquilo que não existe, que não foi feito. Existências concebidas para ser na medida em que não são, na medida em que cedem espaço para a instauração, fugidia e presente, daquilo que as desacreditará enquanto existência.

E se disso se trata, se é essa a natureza das coisas, então a verdade apta a exprimi-las é justamente a ilusão, a verdade que é não sendo. Ora, a verdade, segundo uma categorização racional, se define precisamente por estar óbvia, patente. Portanto, a verdade de que o sujeito dá notícias se configura por meio daquilo que a verdade, em linhas ordinárias, não pode ser: algo desconhecido, ainda obscuro. Sublinhe-se que o sujeito não parece pretender revelar essa verdade, como se esse dado desconhecido precisasse ser desencoberto, a fim de que ela se desvelasse. Diferentemente, ele estaria se apropriando dela tal qual ela se apresenta, pois tal é o seu genuíno modo de se dar ao entendimento, como a "unknown truth".

Sendo essa a verdade da qual o sujeito se constitui como intérprete, torna-se presumível que, ao ser dada à apreciação alheia, sua compreensão por parte desse outro 
- em primeira instância, o leitor - não se fará sem possíveis entraves e lacunas. Contudo o sujeito não demonstra se afligir com essa problemática. Pode-se mesmo propor que, se, de fato, ele se configura como intérprete, então ele se desobrigaria de executar essa função de modo a aclarar ou revelar o que quer que seja. E a verdade pincelada por ele um intérprete que é não sendo -, se configura como algo a ser apropriado por ele mesmo; ou seja, o principal destinatário do eu que ali fala é o eu que ali está.

E assim se forma uma hipótese à questão dos ecos da tradição romântica no soneto: o desconcerto, ou mais precisamente, a alienação do sujeito perante o mundo e os outros, é verificável, à semelhança do que se dá com o eu romântico, mas os motores para tal são já distintos. Pois, enquanto a radicalização no eu, para os românticos, fornece um meio de evasão a um cenário ou realidade que os desagrade e frustre, no soneto "XXXI", essa radicalização é reflexo da resolução do eu em não anelar por aquilo que, em sendo impossível de se realizar, resgatar ou compreender, possa vir a frustrá-lo caso seja desejado. Em vez de se tratar de uma evasão à impossibilidade de se obter aquilo que se anela, trata-se de uma evasão do próprio ato de anelar.

Há ainda uma divergência mais sutil em relação a esse eu romântico, pois ao passo em que este pode ver-se alienado até de si, o mesmo não se dará com o sujeito do poema de Pessoa. Pelo contrário, ele padece de um excesso de consciência acerca de si mesmo. E, estando assim constituído, as debilidades e limitações que o assolam no âmbito (mais superficial) da natureza, não serão determinantes o suficiente para anulá-lo por completo de si, mas serão apenas sensações - semelhantes a quaisquer outras desse âmbito -, a serem interpretadas por meio de sua linguagem hermética que, por sua vez, é o afloramento estético dessa sua consciência de nível superior e mais penetrante.

Assim, esse sujeito pessoano sabe expressar quem é, mas sua maestria está em saber fazê-lo sem dizer quem é ou sem explicitar que saiba fazê-lo, correndo mesmo o risco de perder-se enquanto sujeito, da perspectiva do outro, devido a não estar comprometido em levar aquele que entre em contato com a verdade acerca de quem ele seja, à compreensão dessa verdade. Diferentemente, restará a esse outro apenas uma pista de como proceder: depositar sua esperança justamente na verdade desconhecida, em vez de tentar desvendar o desconhecido na esperança de encontrar a verdade.

Portanto esse hermetismo ambíguo, em que a voz poética interpreta ao mesmo tempo em que veda as notas e as notícias de uma verdade que é ilusão, se mostra como um poderoso alicerce da obra - e aqui o artigo ousa tomar o termo "obra" em seu sentido mais amplo. E não obstante a essa complexidade de apropriação de tal obra por parte daquilo que se pode chamar de público (leitor e Estado), Fernando Pessoa é não apenas canônico, mas também um grande canonizador da poesia em língua portuguesa. Embora o porquê disso contenha uma parcela de imperscrutável, nas próximas discussões, a partir de uma breve análise da ode "Sim", buscar-se-á lançar algumas hipóteses para tal. Desse modo, ofereça-se o poema (PESSOA, 1965, p. 286):

SIM, sei bem

Que nunca serei alguém.

Sei de sobra

Que nunca terei uma obra. 
Sei, enfim,

Que nunca saberei de mim.

Sim, mas agora,

Enquanto dura esta hora,

Este luar, estes ramos,

Esta paz em que estamos,

Deixem-me crer

O que nunca poderei ser.

Enquanto dura a verdade da poesia, aquilo que nunca poderá ser, é. Nas linhas mesmas, nos versos mesmos do poema, se instaura uma realidade que, no entanto, deverá, necessariamente, ser entendida e sentida como ilusão. Uma verdade desconhecida não por estar velada (ao menos não para o poeta), mas por não se dar a conhecer enquanto verdade, enquanto fato.

Assim os ditos que traz à tona são como um "world made just to be disbelieved", e a noção do que seja o "Sim" passa inescapavelmente pelo "Não". O "nunca" torna-se "já", "agora", e aquele que nunca será alguém e nunca terá uma obra, é já precisamente o alguém que escreve a obra agora e sempre, no ato da leitura, em que se lê, por uma afirmação, a negação da realidade que se oferece plena ao leitor: a obra está diante dele, e o seu autor é nada menos que um dos maiores poetas da literatura portuguesa.

Do ponto de vista da coletividade portuguesa, enquanto Estado e povo, enquanto leitores entendidos e leigos, enquanto intelectuais e literatos, enfim, da perspectiva de todo português que possa, por diferentes meios e motivações, entrar em contato com a obra de Fernando Pessoa, há que se considerar os entraves ligeiramente tratados aqui, somados a ainda outros não contemplados, na sua qualidade de complicadores à compreensão e apropriação dessa obra. Uma base de fundamental importância em língua inglesa, a dispersão da unidade autoral em heterônimos (poéticos e críticos), a escassez de obras éditas, em relação às inéditas, à ocasião da morte do autor, o caos quase quimérico em que tais obras foram deixadas, são alguns desses complicadores.

Porém, com base nas particularidades, acima assinaladas, do poema "Sim", pretende-se lançar luzes, já em linhas de conclusão, sobre um outro desses complicadores, relativo aos componentes mais básicos da linguagem: conteúdo e forma.

Assim, questiona-se: como um poeta que, no nível do conteúdo, se inferioriza, acaba por ser aclamado como um poeta maior, entrando para o cânon?

Uma primeira hipótese se delineia ao se considerar o alcance retórico, leia-se, programático, dessa inferiorização, conforme já se esboçou na breve análise anterior. Contudo, uma segunda também se faz destacável, qual seja: o mecanismo, ou mesmo a postura, da canonização intraliterária. Isto é, quando os poetas, os literatos se canonizam entre si, e a preocupação em fechar o canal comunicativo entre destinatário e remetente, nos termos das teorias da linguagem, se perde ou é minimizada a ocasiões ou situações muito restritas, pois, nessa empresa comunicativa de que a obra literária se torna o produto, se buscaria a aceitação e apreciação de outros literatos e dos intelectuais de relevo, de real significação no cenário da alta literatura e da arte como um todo. 
No entanto, considerada essa postura, diga-se, exclusivista ou excludente, o que poderia motivar o alçamento de um dado poeta à posição canônica, do ponto de vista de uma coletividade, de uma nação como um todo?

Não sendo, contudo, uma resposta a essa problemática, a inferência que se esboçará servirá de conclusão a um trabalho que, desde seu início, não pretendeu encerrar qualquer discussão, mas pelo contrário, propô-las, sugeri-las e, talvez com algum sucesso, esmiuçá-las.

Reinvoque-se a ode "Sim", e proponha-se que: sim, o poeta não está preocupado em se fazer entender, e não teme que seus escritos possam desaboná-lo ou obscurecer sua genialidade frente àqueles que o lerem (sejam eles quem for), pois, diante da complexidade e da multiplicidade que engendra, ele se firma numa dada unidade, definida por um atributo intrínseco e inalienável de sua poesia: a superioridade estética.

Dessarte, ele se vê apto a atingir o extremo de afirmar sua inferioridade no nível do conteúdo, por estar ciente de que, no âmbito em que de fato se instaura a boa poesia, isto é, no nível da forma, não há o que poderá desaboná-lo enquanto poeta genial. Vê-se também seguro para afirmar que jamais terá uma obra, pois o está fazendo dentro, no interior de uma. De modo mais abrangente, pode-se apontar que essa segurança se estenderá à afirmação do que quer que seja, pois, sem deixar de estar numa laboriosa relação programática com o conteúdo, a forma como o fará superará em relevo e significância aquilo que ele venha a dizer. E, por fim, esse paradoxo estilístico e formal não permitirá que a afirmação se sustente enquanto verdade imediata, a ser coletivamente aceita; pelo contrário, no encontro com um conteúdo provocador, tal qual o da ode "Sim", expresso da forma como o foi, bem como no encontro de qualquer outro conteúdo que Fernando Pessoa tenha se proposto a tratar poeticamente, a verdade que estará muito mais propensa a ser coletivamente aceita é a de se estar diante de uma obra da alta literatura:

Pessoa escreveu milhares de páginas para dizer que ele não era nada, que só fingia, que afinal nada valia a pena, inclusive e sobretudo o esforço de escrever. Esse paradoxo, e o paradoxo final de ter encontrado postumamente milhares de leitores, parece a última mágica executada pelo extraordinário prestidigitador que ele foi. (PERRONE-MOISÉS, 2001, s/p)

Assim, ainda que dotada de meandros problemáticos, tal qual um labirinto muito extenso, a relação entre a obra e os seus receptores pode se estabelecer e se manter de modo seguro, nesse fio de Ariadne a que corresponde a sua superioridade estética, a unidade pela qual todas as máscaras de Pessoa apontam para uma mesma direção, para um mesmo rosto. 


\section{REFERÊNCIAS BIBLIOGRÁFICAS}

BARROS, Fernando Monteiro de. O mal-do-século no Romantismo inglês. Rio de Janeiro: UFRJ. Disponível em: <http://www.filologia.org.br/soletras/8/11.htm>. Acesso em: 07 dez. 2010.

MOISÉS, Carlos Felipe. Fernando Pessoa: almoxarifado de mitos. São Paulo: Escrituras, 2005. Disponível em: < http://lazer.hsw.uol.com.br/fernando-pessoa3.htm >. Acesso em: 06 dez. 2010.

PERRONE-MOISÉS, Leyla. Fernando Pessoa: aquém do eu, além do outro. São Paulo: Martins Fontes, 2001. Disponível em: <http://lazer.hsw.uol.com.br/fernandopessoa3.htm>. Acesso em: 06 dez. 2010.

PESSOA, Fernando. Obra Poética. Rio de Janeiro: Aguilar, 1965.

WORDSWORTH, William. [1807] "Intimations of Immortality from Recollections of Early Childhood" In: Poems in Two Volumes. Disponível em: <http://www.bartleby.com/101/536.html>. Acesso em: 07 dez. 2010.

\section{ANEXO}

Tradução livre do soneto "XXXI"

EU SOU MAIS VELHO do que a Natureza e o Tempo dela

Por toda a atemporal era da Consciência afora

E minha adulta obliteração da terra

Onde eu nasci um desterrado não me torna.

Ah, e através do crepúsculo meus intuitivos pensamentos fogem

Dos anelos por aquela terra onde minha infância sonhou,

A qual não posso recordar em cor ou molde

Mas assombra minhas horas como algo que cintilou

E não é rememorado como luz, todavia

Nem para a esquerda ou para a direita imaginado;

E tudo ao meu redor me parece como se fosse morta a vida

E o mundo feito apenas para ser desacreditado.

Assim, na verdade desconhecida minha esperança lanço; no entanto

Como senão através da esperança a verdade desconhecida alcanço? 